\title{
Duration of Cunnilingus Predicts Estimated Ejaculate Volume in Humans: a Content Analysis of Pornography
}

\author{
Michael N. Pham ${ }^{1}$ • Austin John Jeffery ${ }^{1}$ - Yael Sela ${ }^{1}$ - Justin T. Lynn ${ }^{2} \cdot$ Sara Trevino $^{2}$ • \\ Zachary Willockx ${ }^{1} \cdot$ Adam Tratner $^{1} \cdot$ Paul Itchue $^{1} \cdot$ Todd K. Shackelford $^{1}$ • \\ Bernhard Fink $^{3}$ • Melissa M. McDonald ${ }^{1}$
}

Published online: 10 May 2016

(C) Springer International Publishing 2016

\begin{abstract}
Humans perform copulatory behaviors that do not contribute directly to reproduction (e.g., cunnilingus, prolonged copulation). We conducted a content analysis of pornography to investigate whether such behaviors might contribute indirectly to reproduction by influencing ejaculate volume - an indicator of ejaculate quality. We coded 100 professional pornography scenes depicting the same male actor copulating with 100 different females, affording control for between-male differences in estimated ejaculate volume. Coders visually estimated ejaculate volume and recorded the time the actor spent engaged in cunnilingus, penile-vaginal penetration, and in any physical contact with his partner. We found support for the hypothesis that a man who spends more time performing cunnilingus produces an ejaculate with greater estimated volume, even after controlling statistically for the age and attractiveness of the actress, and time spent in physical contact with his partner. Additionally, we tested the ejaculate adjustment hypothesis for prolonged copulation and found no support. Prolonged copulation does not facilitate production of an ejaculate with greater estimated volume, even after controlling statistically for time spent in physical contact with a partner. This research is the first to use content analysis to document that pre-ejaculatory copulatory behavior predicts estimated ejaculate volume and also is the first to document
\end{abstract}

Michael N. Pham

mnpham@oakland.edu

1 Department of Psychology, Oakland University, Rochester, MI, USA

2 Department of Psychology, California State University, Fullerton, CA, USA

3 Institute of Psychology and Courant Research Center Evolution of Social Behavior, University of Göttingen, Göttingen, Germany a relationship between the time spent performing cunnilingus and ejaculate quality.

Keywords Cunnilingus · Prolonged copulation · Content analysis $\cdot$ Pornography $\cdot$ Ejaculate volume

"Ejaculate quality" is a composite of ejaculate traits (e.g., sperm motility, sperm viability, sperm number) that affect fertilizing ability (Simmons and Fitzpatrick 2012). Ejaculate volume is another trait indicator of quality. For example, nonsperm substances in semen - which comprise the majority of the ejaculate's volume - may promote fertilization by promoting sperm motility, reducing the risk of preeclampsia and suppressing the female immune response that would otherwise attack foreign bodies - including sperm (Burch and Gallup 2006; Davis and Gallup 2006). According to the World Health Organization (WHO 2010), low volume ejaculates indicate infertility.

In humans, sexual arousal influences ejaculate volume between ejaculates within men, with greater sexual arousal associated with increased ejaculate volumes (WHO 2010). For example, men produce ejaculates with greater volume from copulation (i.e., more arousing) than from masturbation (i.e., less arousing; Zavos 1985; Zavos and Goodpasture 1989), and during copulation uninterrupted until ejaculation (i.e., more arousing) than during coitus interruptus (i.e., less arousing; Zavos et al. 1994). Men produce higher quality masturbatory ejaculates when they spend more (versus less) time sexually aroused (Pound et al. 2002) and when they view more (versus less) sexually arousing stimuli (Kilgallon and Simmons 2005; Leivers et al. 2014; Joseph et al. 2015). Men who report greater sexual arousal report more intense orgasm, more forceful ejaculation (Pham et al. 2013), and produce an ejaculate with greater volume (van Rouen et al. 1996). 
Because there are non-trivial costs to producing ejaculates (WHO 2010), men experience greater arousal when the reproductive benefits outweigh the costs of producing a higher quality, larger volume ejaculate. For example, men are sensitive to behavioral, visual, auditory, and olfactory cues to female fertility (Haselton and Gildersleeve 2011). Men exposed to a woman's scent produced at high (versus low) fertility experience a testosterone surge and report greater sexual interest (Doty et al. 1975; Miller and Maner 2009; CerdaMolina et al. 2013), consistent with the idea that men are sexually aroused by high-fertility cues. Additionally, men are aroused by cues to sperm competition; Pham and Shackelford (2014) review evidence that men are sensitive to sociosexual, personality, visual, and olfactory cues to sperm competition. For example, pornography depicting two men with a woman is more arousing (Pound 2002; McKibbin et al. 2013) and leads men to produce more competitive masturbatory ejaculates than pornography depicting multiple women (Kilgallon and Simmons 2005). Men exposed to sperm competition cues (relative to men not exposed to sperm competition cues) report greater sexual interest (Shackelford et al. 2002, 2007; Camilleri and Quinsey 2009; Pham and Shackelford 2013a), greater sexual arousal (Pound 2002; McKibbin et al. 2013), and produce higher quality ejaculates (Baker and Bellis 1993; Kilgallon and Simmons 2005; Leivers et al. 2014; Joseph et al. 2015). Thus, men experience greater sexual arousal in sociosexual circumstances (e.g., higher conception risk, higher sperm competition risk) in which the reproductive benefits outweigh the costs of producing higher quality, greater volume ejaculates.

Although humans and non-humans perform sexual behaviors that do not contribute directly to reproduction (e.g., cunnilingus, prolonged copulation), such behaviors might contribute indirectly to reproduction (e.g., affecting sexual arousal and consequent ejaculate volume, more effective semen displacement, increasing likelihood of female orgasm). Sexual arousal fluctuates during the course of a single sexual event (Zavos et al. 1994). The current research investigates whether ejaculate volume is predicted by cunnilingus and by prolonged copulation in humans.

Males of many mammalian species perform cunnilingus in sociosexual circumstances (e.g., higher conception risk, higher sperm competition risk) in which the reproductive benefits outweigh the costs of producing higher quality, greater volume ejaculates. For example, males perform cunnilingus to assess a female's fertility by sniffing and licking her genitals (i.e., cunnilingus) to gather scent cues to her fertility status. Male cotton-top tamarins (Saguinus Oedipus) that smell a female's scent marks produced at high fertility - relative to at low fertility - experience more frequent penile erections and perform more mounting behaviors (Ziegler et al. 1993). Gathering scent cues to fertility status also may explain why males of several mammalian species more frequently perform cunnilingus on high fertility females than on low fertility females, including dogs (Dunbar 1977; Kiddy et al. 1978), hamsters (Mesocricetus auratus: Murphy 1973; Johnston 1974), bovine (Nishimura et al. 1991; Sankar and Archunan 2004), ring-tailed lemurs (Lemur catta: Palagi et al. 2003), and pygmy marmosets (Cebuella pygmaea: Soini 1987). Male Indian flying foxes (Pteropus giganteus) that spend more time performing cunnilingus on a female also spend more time copulating with her (Maruthupandian and Marimuthu 2013), and Maruthupandian and Marimuthu have interpreted this relationship with respect to sperm competition theory. Thus, among mammals, cunnilingus may influence sexual arousal and consequent sperm competition tactics (e.g., mounting behaviors, copulatory thrusting, and ejaculate adjustment).

Much evidence suggests an evolutionary history of cunnilingus in humans. Cunnilingus occurs in many cultures (e.g., Iwawaki and Wilson 1983; Lurie et al. 1995; Guadamuz et al. 2010), including pre-industrial cultures (Hewlett and Hewlett 2010), indicating that cunnilingus is not a culture-specific practice. Cunnilingus is depicted frequently in pornography, and pornography appeals to evolved mechanisms: Humans do not possess adaptations to experience sexual arousal in response to viewing computer images, but to viewing "real-life" humans with whom they can copulate (Malamuth 1996). Some ancestral cave paintings depict humans engaged in behaviors that resemble cunnilingus, but Angulo and García (2005) caution that these depictions are ambiguous and, therefore, may be interpreted in other ways. Cunnilingus occurs across many species (Soini 1987; Nishimura et al. 1991; Palagi et al. 2003; Maruthupandian and Marimuthu 2013), and behaviors that occur across species indicate the possibility of convergent adaptations.

In humans, men may perform cunnilingus to increase their sexual arousal and consequent ejaculate volume, particularly in sociosexual circumstances (e.g., high conception risk, high sperm competition risk) in which the reproductive benefits outweigh the costs of producing higher quality ejaculates. The nationally representative National Health and Social Life Survey found that while $71 \%$ of men find performing cunnilingus either very appealing or somewhat appealing, and only $19 \%$ find it not at all appealing, $60 \%$ of women find receiving cunnilingus very appealing or somewhat appealing, and $28 \%$ report that it is not at all appealing (Laumann et al. 1992), which suggests that men may also perform cunnilingus to make their partner more receptive to penile-vaginal sex. Men who report spending more time performing cunnilingus during their most recent sexual encounter report greater sexual arousal compared to their typical sexual encounters (Pham et al. 2013). Cunnilingus may also be more often employed in contexts that present greater sperm competition risk (reviewed in Pham and Shackelford 2014). Men who rate female genital odors that are produced during high fertility (relative to low fertility) as more pleasant smelling experience 
a testosterone surge and report greater sexual interest (Doty et al. 1975; Cerda-Molina et al. 2013). Men who report spending more time performing cunnilingus report greater sexual arousal (Pham et al. 2013), and cunnilingus may be related to conception risk and to sperm competition risk (reviewed in Pham and Shackelford 2014). Men who spend more time performing cunnilingus may receive more exposure to copulins - substances excreted by the vagina that may increase male sexual arousal (Juette 1995). Men typically perform cunnilingus before they copulate and ejaculate (Halpern and Sherman 1979), suggesting that cunnilingus may influence sexual arousal and consequent sperm competition tactics (e.g., copulatory thrusting, ejaculate adjustment).

Because cunnilingus increases male sexual arousal and because male sexual arousal is correlated with ejaculate quality, we hypothesize that a man who spends more time performing cunnilingus will produce an ejaculate with greater volume (hypothesis 1).

The ejaculate adjustment hypothesis of prolonged copulation proposes that men perform prolonged copulations to increase their sexual arousal and consequent ejaculate quality (Pham et al. 2013). Men who report their partner to be more sexually attractive (and, therefore, presenting greater sperm competition risk; Goetz et al. 2005) spend more time copulating at the couple's next copulation (Goetz et al. 2005), and men who masturbate to images of more (versus less) attractive women produce higher quality ejaculates (Leivers et al. 2014). Men who spend more time masturbating produce a higher quality ejaculate (Pound et al. 2002). Thus, prolonged copulation may increase sexual arousal and consequent ejaculate volume in a manner predicted by sperm competition theory (see Pham and Shackelford 2014). Thus, we hypothesize that a man who spends more time copulating will produce an ejaculate with greater volume (hypothesis 2).

Humans and non-humans perform many behaviors during a single copulatory event (e.g., touching, kissing), each of which may affect male sexual arousal and copulatory behaviors. For example, bats that spend more time performing fellatio (Cynopterus sphinx; Tan et al. 2009) or cunnilingus (Pteropus giganteus; Maruthupandian and Marimuthu 2013) spend more time copulating, and similar relationships have been documented in humans (Pham et al. 2013). Therefore, in tests of the hypotheses, we control statistically for the total time the performers spend in physical contact.

We also control statistically for the actress's age and attractiveness - each of which is a cue to female fertility (Buss 1989) - because males adjust their ejaculate quality as a function to their sexual partner's fertility (Goetz et al. 2005; Leivers et al. 2014). In particular, we focus on body attractiveness because body attractiveness (more than face attractiveness) provides information about a woman's current fertility (Confer et al. 2010). Indeed, men prioritize body attractiveness (over face attractiveness) when selecting short-term mating partners (Confer et al. 2010; Currie and Little 2009) - the very mating context that pornography depicts.

Previous studies on humans that assess the relationship between sexual behavior and ejaculate quality relied on indirect measures of sexual behavior to protect participant privacy (e.g., researchers measure the time participants spend in a private room to indirectly assess the time they spend masturbating: Pound et al. 2002; participants self-report whether they ejaculated via masturbation or via copulation: Dehghani et al. 2004). To address these limitations, we tested the hypotheses by securing more direct measures of sexual behaviors: Using content analysis of professional pornography scenes, coders assessed the time the male actor spent performing cunnilingus and performing vaginal penetration, the total time the partners spent in physical contact, and visually estimated ejaculate volume.

\section{Method}

We conducted a content analysis of professional pornography scenes. We implemented five inclusion criteria for selecting pornography scenes for analysis. First, we included only scenes depicting one man having sex with one woman because the number and sex of performers affect ejaculate quality (Kilgallon and Simmons 2005). Second, we included only scenes in which the camera presented a clear view of the ejaculate. This criterion excluded scenes in which ejaculation occurred either inside the woman or outside the camera's view, or in which no ejaculation occurred. Third, because ejaculate volume varies between men (WHO 2010), we selected only scenes starring the same male actor. We used Internet Adult Film Database (IAFD.com) - a website containing biographical information for over 100,000 adult performers (IAFD 2015) - to verify that the same male actor was depicted across all the selected scenes. Fourth, we included only scenes that began before performers made physical contact and that ended after ejaculation. Fifth, we included only scenes in which the man did not wear a condom because condoms affect sexual arousal (see MacDonald et al. 2000). We searched websites providing free access to pornography: keezmovies.com, pornhub.com, xnxx.com, xhamster.com, youporn.com, and xvideos.com. We used IAFD.com to ensure that each scene depicted a different actress and that all scenes depicted the same actor.

Six coders (two women, four men) coded a total of 100 scenes. All coders were blind to the hypotheses. Five of the six coders independently estimated the volume of the ejaculate (in teaspoons), and two of the six coders recorded the number of seconds the performers spent engaged in cunnilingus, vaginal penetration, and any physical contact. Multiple start times and stop times were documented when behaviors occurred more than once in a scene (e.g., actor performed cunnilingus, then 
performed vaginal penetration, then resumed cunnilingus), and the duration of these activities was summed if they occurred prior to ejaculation. Coders were instructed to estimate the total ejaculate volume by observing the number and quantity of each ejaculatory spurt, starting from when the ejaculate left the penis until it appeared after landing. Each coder provided one estimate of ejaculate volume. Nine scenes were excluded because they could not be coded for all variables due to missing data (e.g., scenes were removed from websites during the data collection period), leaving 91 scenes for analyses.

We secured ratings of each actress's body attractiveness from pornstarnetwork.com - a mega-site containing 56 pornography websites and 11,300 pornography scenes (Pornstar Network 2015). Users submit body attractiveness ratings of individual actresses on a 10-point system $(1=$ horrible, $10=$ perfect). The website displays average ratings of each actress based on hundreds of user-submitted ratings. Using data we collected from the Internet Adult Film Database (IAFD.com), we recorded the year in which each actress was born and the year in which her scene was released.

\section{Results}

We constructed an estimated ejaculate volume variable from the mean of the estimates of ejaculate volume $(\alpha=0.78)$. We constructed three time variables (any physical contact, cunnilingus, penile-vaginal penetration) from the means of the estimates of each of those variables $(\alpha=0.95,0.84$, and 0.91 , respectively). Using data from AIFD, we calculated each actress's age by subtracting the year in which the scene was released from the year in which the actress in that scene was born. We used data secured from pornstarnetwork.com to measure each actress's body attractiveness.

Table 1 presents descriptive statistics and zero-order correlations among the key variables. To test the hypothesis that a man who spends more time performing cunnilingus will produce an ejaculate with greater estimated volume (hypothesis 1), we conducted a hierarchical multiple regression (see Table 2). In step 1, we entered the age and attractiveness of the actress and the time spent in any physical contact (after subtracting from this variable the time spent performing cunnilingus) to predict estimated ejaculate volume. In step 2 , we added the time spent performing cunnilingus into the model. Consistent with hypothesis 1 , when the actor spent more time performing cunnilingus, he produced an ejaculate with greater estimated volume $(\beta=0.27, t=2.32, p<0.05)$. To test the normality assumption of linear regression, we conducted Kolmogorov-Smirnov and Shapiro-Wilk tests on the residuals of this model. Both tests yielded non-significant results, indicating that normality assumptions were met: $D$ $(85)=0.06, p=0.20 ; S-W(85)=0.98, p=0.25$.
To test the ejaculate adjustment hypothesis for prolonged copulation (hypotheses 2), we conducted a hierarchical multiple regression (see Table 3). In step 1, we entered the age and attractiveness of the actress and the time spent in any physical contact (after subtracting from this variable the time spent performing vaginal penetration). In step 2 , we added the time spent performing vaginal penetration into the model. Results were inconsistent with hypothesis 2 . When the actor spent more time performing vaginal penetration, he did not produce an ejaculate with greater estimated volume $(\beta=-0.03$, $t=-0.25, p=0.80$ ). To test the normality assumption of linear regression, we conducted Kolmogorov-Smirnov and ShapiroWilk tests on the residuals of this model. Both tests yielded non-significant results, indicating that normality assumptions were met: $D(89)=0.07, p=0.20 ; S-W(89)=0.98, p=0.34$.

Because of professional video editing, some scenes had interruptions. Although these edits likely removed behaviors that were irrelevant to our hypotheses (e.g., editing out times during which performers readjusted or changed positions), such editing may have resulted in inaccurate coding of the target variables. Therefore, we conducted a separate set of analyses in which we excluded all scenes that contained video-edited interruptions during sexual activity. After applying this exclusion criterion, we conducted the same analyses described above. Hypothesis 1 remained supported $(n=68$, $\beta=0.33, t=2.53, p<0.05$ ), and hypothesis 2 remained unsupported $(n=68, \beta=-0.06, t=-0.41, p=0.69)$.

\section{Discussion}

The results of the current research support the hypothesis that a man who spends more time performing cunnilingus produces an ejaculate with greater estimated volume (hypothesis 1), even after controlling for potential confounds, including the total time the performers spent in physical contact and the age and attractiveness of the actress. We did not find support for the hypothesis that a man who spends more time copulating will produce an ejaculate with greater estimated volume (hypothesis 2). The current research is the first to document a relationship between the time spent performing cunnilingus and ejaculate quality.

An alternative hypothesis for prolonged copulation is that men perform prolonged copulations to spend more time displacing rival semen that may be in a woman's reproductive tract (Goetz et al. 2005). Gallup et al. (2003) used artificial genitals and artificial semen and provided evidence that the shape of the human penis facilitates semen displacement from the vagina during copulatory thrusting. Goetz et al. (2005) found that men who perceive their partner to be more attractive (i.e., presenting greater sperm competition risk) perform more semen displacement copulatory behaviors (e.g., deeper, more vigorous copulatory thrusts), including prolonged 
Table 1 Zero-order correlations among key variables $(n=85)$

\begin{tabular}{lllllll}
\hline & Mean & SD & 1 & 2 & 3 & 4 \\
\hline 1 Estimated ejaculate volume & 2.48 teaspoons & 0.64 & & & & \\
2 Physical contact & $1437.11 \mathrm{~s}$ & 375.36 & -0.02 & & & \\
3 Cunnilingus & $87.14 \mathrm{~s}$ & 97.38 & 0.21 & $0.41^{* *}$ & & \\
4 Penile-vaginal penetration & $689.33 \mathrm{~s}$ & 324.69 & 0.02 & $0.21^{*}$ & $0.32^{* *}$ & \\
5 Age & 25.56 years & 6.50 & -0.08 & 0.12 & $0.26^{*}$ & -0.00 \\
6 Attractiveness & 9.14 & 1.07 & 0.04 & -0.03 & 0.20 & 0.06 \\
\hline
\end{tabular}

${ }^{*} p<.05$ and ${ }^{* *} p<.01$

copulations. Although the results of the current research did not support the ejaculate adjustment hypothesis for prolonged copulation, future research can extend the results of Goetz et al. by conducting a content analysis of amateur pornography to assess whether men who copulate with a more attractive woman also spend more time copulating with her.

The current research is guided by a male perspective because male sexual arousal mediates the relationship between copulatory behaviors and ejaculate quality. However, women play significant roles in copulatory behavior. For example, men perform cunnilingus to satisfy a woman (Pham and Shackelford 2013b), often upon her request (Backstrom et al. 2012), and women can determine the duration of copulation depending on the sexual position (e.g., when a woman is mounted on top of a man). Women also have reproductive interests in their partner's ejaculate quality. When women's interests and men's interests are aligned (i.e., sexual cooperation), women may benefit from their partner's higher quality ejaculate (e.g., when a couple is attempting to conceive). Thus, the results of the current research should be interpreted not as the exclusive product of a male strategy, but instead as the product of male and female sexual strategies that are

Table 2 Hierarchical multiple regression analysis assessing the relationship between the time spent performing cunnilingus and estimated ejaculate volume, controlling statistically for the total time spent in physical contact and the age and attractiveness of the actress

\begin{tabular}{lllll}
\hline & $\beta$ & S.E. & $t$ & $p$ value \\
\hline Step 1 $\left(r^{2}=0.01\right)$ & & & & \\
$\quad$ Age & -0.07 & 0.01 & -0.67 & 0.50 \\
Attractiveness & 0.03 & 0.06 & 0.31 & 0.76 \\
$\quad$ Physical contact & -0.07 & 0.00 & -0.66 & 0.51 \\
Step 2 $\left(r^{2}=0.08\right)$ & & & & \\
Cunnilingus & 0.27 & 0.00 & 2.32 & 0.02 \\
Age & -0.14 & 0.01 & -1.27 & 0.21 \\
Attractiveness & -0.03 & 0.06 & -0.23 & 0.82 \\
Physical contact & -0.12 & 0.00 & -1.12 & 0.26 \\
\hline
\end{tabular}

$\beta$ standardized beta coefficient, S.E. standard error of $\beta, t$ test statistic associated with $\beta$ variably in conflict or cooperation (see Shackelford and Goetz 2012).

Professional pornography - in contrast with amateur pornography - uses superior camerawork and, therefore, produces higher quality video of ejaculations. However, producers and directors of professional pornography may dictate the time professional actors spend performing sexual behaviors. Thus, the duration of sexual behaviors in professional pornography may not accurately reflect the duration of these behaviors in normal, natural circumstances. Furthermore, having sex publicly in exchange for payment from viewers (i.e., professional pornography) likely did not occur in ancestral environments. People might perform different sexual behaviors in amateur pornography than in professional pornography. However, because ejaculate adjustment is an autonomic reflex - unconsciously controlled by the male sexual response cycle (Jones and Lopez 2013) — the relationships between sexual behaviors and estimated ejaculate volume documented in the current research might be generalizable to normal, natural circumstances. Nevertheless, future

Table 3 Hierarchical multiple regression analysis assessing the relationship between the time spent performing penile-vaginal penetration and estimated ejaculate volume, controlling statistically for the total time spent in physical contact and the age and attractiveness of the actress

\begin{tabular}{lllll}
\hline & $\beta$ & S.E. & $t$ & $p$ value \\
\hline Step 1 $\left(r^{2}=0.01\right)$ & & & & \\
$\quad$ Age & -0.01 & 0.01 & -0.91 & 0.36 \\
$\quad$ Body attractiveness & 0.04 & 0.06 & 0.34 & 0.74 \\
$\quad$ Physical contact & -0.02 & 0.00 & -0.19 & 0.85 \\
Step 2 $\left(r^{2}=0.01\right)$ & & & & \\
$\quad$ Penile-vaginal penetration & -0.03 & 0.00 & -0.25 & 0.80 \\
Age & -0.10 & 0.01 & -0.88 & 0.38 \\
Body attractiveness & 0.04 & 0.06 & 0.34 & 0.73 \\
Physical contact & -0.04 & 0.00 & -0.29 & 0.77 \\
\hline
\end{tabular}

We standardized the target variables before conducting multiple regression

$\beta$ standardized beta coefficient, S.E. standard error of $\beta, t$ test statistic associated with $\beta$ 
research might attempt to replicate results of the current research using content analyses of amateur pornography.

A limitation of the current research is reliance on visual estimates rather than actual assessments of ejaculate volume. However, our hypotheses (e.g., time spent performing cunnilingus is positively correlated with ejaculate volume) depend only on reliable estimates of volume - not on the accuracy of ejaculate volume estimates. In other words, it is irrelevant whether coders correctly identified ejaculate volumes in teaspoons, only that they correctly identified the relative differences in ejaculate volumes between scenes. The independent coders achieved reasonable inter-rater agreement in estimating ejaculate volume $(\alpha=0.78)$, indicating that these estimates can be made with sufficient reliability to warrant inclusion in empirical analyses. Nevertheless, future research could secure motion capture video of participants during copulation to directly measure sexual behavior and could collect the ejaculate (e.g., via condom) produced from that copulation to directly measure ejaculate volume.

Additionally, we coded scenes in which the man ejaculated outside the vagina. Such ejaculations do not result in fertilizations and, therefore, represent non-adaptive encounters. Indeed, men produce lower quality ejaculates when they withdraw their penis from the vagina immediately prior to ejaculation (Zavos et al. 1994). Future research can employ fluorescent dyes in which researchers can measure ejaculate volume inside the female reproductive tract, a methodology that has been used in non-human research measuring the fertilizing success of ejaculates (e.g., Lymbery et al. 2016).

We could not determine when the actor last ejaculated before each scene. This may explain why the two regression models accounted for a small percentage of the variance: The duration of abstinence is consistently one of the strongest predictors of ejaculate volume (WHO 2010). Indeed, in studies that investigate the strategic adjustments in ejaculate quality, participants are instructed to abstain for at least $48 \mathrm{~h}$ prior to submitting their ejaculates for analysis (Joseph et al. 2015; Kilgallon and Simmons. 2005; Leivers et al. 2014) Future replications of the current research could secure information about the most recent ejaculation prior to each copulation to increase the explanatory power of the models.

Additionally, the small effect size may be attributable to the human olfactory system. Humans are less dependent on chemosensory systems than are other primates (Gilad et al. 2003). The relationship between cunnilingus and ejaculate quality in humans may be remnants of adaptations found in species closely related to humans (i.e., other primates). If this is the case, then we expect much stronger effect sizes when replicating the current research to non-human primates.

The quality of men's masturbatory ejaculates are dependent on several features of the pornography they consume, including cues to sperm competition (Kilgallon and Simmons 2005) and the actress's mate value (Leivers et al. 2014). Future research could extend our findings by investigating whether men produce different quality ejaculates depending on whether cunnilingus is depicted in the pornography they consume.

Variation in quality between ejaculates has been historically interpreted by andrologists as "noise," with the WHO (2010) recommending that clinicians secure two or three ejaculates from a man to determine his "true" fertility. However, a growing body of research indicates that men strategically adjust their ejaculates (reviewed in Pham and Shackelford 2014) — including adjustments in non-sperm chemicals that affect fertilizing success (Burch and Gallup 2006; Davis and Gallup 2006). The current research contributes to this literature by documenting that men's pre-ejaculatory sexual behavior may affect ejaculate quality. Further, the current research contributes data from humans to the substantial nonhuman literature documenting that copulatory behaviors that do not contribute directly to reproduction contribute indirectly to reproduction by affecting sexual arousal and consequent ejaculate quality. Finally, the current research is the first to document a relationship between the time spent performing cunnilingus and ejaculate quality.

\section{References}

Angulo J, \& García, M (2005). Sexo en piedra. Sexualidad, reproducción y erotismo en época paleolítica. Madrid: Luzán, 5.

Backstrom, L., Armstrong, E. A., \& Puentes, J. (2012). Women's negotiation of cunnilingus in college hookups and relationships. Journal of Sex Research, 49, 1-12.

Baker, R. R., \& Bellis, M. A. (1993). Human sperm competition: ejaculate adjustment by males and the function of masturbation. Animal Behaviour, 46, 861-885.

Burch, R. L., \& Gallup, G. G. (2006). The psychobiology of human semen. In S. M. Platek \& T. K. Shackelford (Eds.), Female infidelity and paternal uncertainty (pp. 141-172). New York: Cambridge University Press.

Buss, D. M. (1989). Sex differences in human mate preferences: evolutionary hypotheses tested in 37 cultures. Behavioral Brain Sciences, 12, 1-14.

Camilleri, J. A., \& Quinsey, V. L. (2009). Testing the cuckoldry risk hypothesis of partner sexual coercion in community and forensic samples. Evolutionary Psychology, 7, 164-178.

Cerda-Molina, A. L., Hernández-Lopez, L., de la O, C. E., ChaviraRamírez, R., \& Mondragón-Ceballos, R. (2013). Changes in men's salivary testosterone and cortisol levels, and in sexual desire after smelling female axillary and vulvar scents. Frontiers in Endocrinology, 4, 1-9.

Confer, J. C., Perilloux, C., \& Buss, D. M. (2010). More than just a pretty face: men's priority shifts toward bodily attractiveness in short-term versus long-term mating contexts. Evolution and Human Behavior, 31, 348-353.

Currie, T. E., \& Little, A. C. (2009). The relative importance of the face and body in judgments of human physical attractiveness. Evolution and Human Behavior, 30, 409-416.

Davis, J. A., \& Gallup, G. G. (2006). Preeclampsia and other pregnancy complications as an adaptive response to unfamiliar semen. In S. M. 
Platek \& T. K. Shackelford (Eds.), Female infidelity and paternal uncertainty (pp. 191-204). New York: Cambridge University Press.

Dehghani, V. A., Khalili, M. A., Khalili, M. A., Zamani, N., \& DrehZereshki, F. (2004). Comparison between semen parameters of ejaculates collected via masturbation versus coitus interruptus. Iranian Journal of Reproductive Medicine, 2, 9-11.

Doty, R. L., Ford, M., Preti, G., \& Huggins, G. R. (1975). Changes in the intensity and pleasantness of human vaginal odors during the menstrual cycle. Science, 190, 1316-1318.

Dunbar, I. F. (1977). Olfactory preferences in dogs: the response of male and female beagles to conspecific odors. Behavioral Biology, 20, 471-481.

Gallup, G. G., Jr., Burch, R. L., Zappieri, M. L., Parvez, R. A., Stockwell, M. L., \& Davis, J. A. (2003). The human penis as a semen displacement device. Evolution and Human Behavior, 24, 277-289.

Gilad, Y., Man, O., Pääbo, S., \& Lancet, D. (2003). Human specific loss of olfactory receptor genes. Proceedings of the National Academy of Sciences, 100, 3324-3327.

Goetz, A. T., Shackelford, T. K., Weekes-Shackelford, V. A., Euler, H. A., Hoier, S., Schmitt, D. P., \& LaMunyon, C. W. (2005). Mate retention, semen displacement, and human sperm competition: a preliminary investigation of tactics to prevent and correct female infidelity. Personality and Individual Differences, 38, 749-763.

Guadamuz, T. E., Kunawararak, P., Beyrer, C., Pumpaisanchai, J., Wei, C., \& Celentano, D. D. (2010). HIV prevalence, sexual and behavioral correlates among Shan, Hill tribe, and Thai male sex workers in Northern Thailand. AIDS Care, 22, 597-605.

Halpern, J., \& Sherman, M. (1979). Afterplay: a key to intimacy. New York: Stein \& Day Pub.

Haselton, M. G., \& Gildersleeve, K. (2011). Can men detect ovulation? Current Directions in Psychological Science, 20, 87-92.

Hewlett, B. S., \& Hewlett, B. L. (2010). Sex and searching for children among Aka foragers and Ngandu farmers of central Africa. African Study Monographs, 31, 107-125.

IAFD [Internet] [Retrieved 2015 September 15] Available from: http:// www.iafd.com.

Iwawaki, S., \& Wilson, G. D. (1983). Sex fantasies in Japan. Personality and Individual Differences, 4, 543-545.

Johnston, R. E. (1974). Sexual attraction function of golden hamster vaginal secretion. Behavioral Biology, 12, 111-117.

Jones, R. E., \& Lopez, K. H. (2013). Human Reproductive Biology. Waltham: Academic.

Joseph, P. N., Sharma, R. K., Agarwal, A., \& Sirot, L. K. (2015). Men ejaculate larger volumes of semen, more motile sperm, and more quality when exposed to images of novel women. Evolutionary Psychological Science, 1, 195-200

Juette, A. (1995). Weibliche Pheromone - Wirkung und Rolle von synthetischen "Kopulinen" bei der versteckten Ovulation des Menschen (Unpublished doctoral dissertation). Vienna: University of Vienna.

Kiddy, C. A., Mitchell, D. S., Bolt, D. J., \& Hawk, H. W. (1978). Detection of estrus-related odors in cows by trained dogs. Biology of Reproduction, 19, 389-395.

Kilgallon, S. J., \& Simmons, L. W. (2005). Image content influences men's semen quality. Biology Letters, 1, 253-255.

Laumann, E. O., Gagnon, J. H., Michael, R. T., \& Michaels, S. (1992). National Health and Social Life Survey [Data set]. Retrieved from http://popcenter.uchicago.edu/data/nhsls.shtml.

Leivers, S., Rhodes, G., \& Simmons, L. W. (2014). Context-dependent relationship between a composite measure of men's mate value and ejaculate quality. Behavioral Ecology, 25, 1115-1122.

Lurie, P., Eugenia, M., Fernandes, L., \& Hughes, V. (1995). Socioeconomic status and risk of HIV-1, syphilis and hepatitis B infection among sex workers in São Paulo State, Brazil. AIDS, 9, 31-37.

Lymbery, R. A., Kennington, W. J., \& Evans, J. P. (2016). Fluorescent sperm offer a method for tracking the real-time success of ejaculates when they compete to fertilise eggs. Scientific Reports, 6, 1-8. doi:10. 1038/srep22689.

MacDonald, T. K., MacDonald, G., Zanna, M. P., \& Fong, G. (2000). Alcohol, sexual arousal, and intentions to use condoms in young men: applying alcohol myopia theory to risky sexual behavior. Health Psychology, 19, 290-298.

Malamuth, N. M. (1996). Sexually explicit media, gender differences, and evolutionary theory. Journal of Communication, 46, 8-31.

Maruthupandian, J., \& Marimuthu, G. (2013). Cunnilingus apparently increases duration of copulation in the Indian flying fox, Pteropus giganteus. Plos One, 8, e59743.

McKibbin, W. F., Pham, M. N., \& Shackelford, T. K. (2013). Human sperm competition in post-industrial ecologies: sperm competition cues predict pornographic DVD sales rank. Behavioral Ecology, 24, 819-823.

Miller, S. L., \& Maner, J. K. (2009). Scent of a woman men's testosterone responses to olfactory ovulation cues. Psychological Science, 21, 276-283.

Murphy, M. R. (1973). Effects of female hamster vaginal discharge on the behavior of male hamsters. Behavioral Biology, 9, 367-375.

Nishimura, K., Utsumi, K., Okano, T., \& Iritani, A. (1991). Separation of mounting-inducing pheromones of vaginal mucus from estrual heifers. Journal of Animal Science, 69, 3343-3347.

Palagi, E., Telara, S., \& Tarli, S. B. (2003). Sniffing behavior in Lemur catta: seasonality, sex, and rank. International Journal of Primatology, 24, 335-350.

Pham, M. N., \& Shackelford, T. K. (2013a). The relationship between objective sperm competition risk and men's copulatory interest is moderated by partner's time spent with other men. Human Nature, $24,476-485$.

Pham, M. N., \& Shackelford, T. K. (2013b). Oral sex as mate retention behavior. Personality and Individual Differences, 55, 185-188.

Pham, M. N., \& Shackelford, T. K. (2014). Human sperm competition: a comparative evolutionary analysis. Animal Behavior and Cognition, $1,410-422$.

Pham, M. N., Shackelford, T. K., Welling, L. L. M., Ehrke, A. D., Sela, Y., \& Goetz, A. T. (2013). Oral sex, semen displacement, and sexual arousal: testing the ejaculate adjustment hypothesis. Evolutionary Psychology, 11, 1130-1139.

Pornstar Network [Internet] [Cited 2015 September 15] Available from: http://support.pornstarnetwork.com/support/faq.php.

Pound, N. (2002). Male interest in visual cues of sperm competition risk. Evolution and Human Behavior, 23, 443-446.

Pound, N., Javed, M. H., Ruberto, C., Shaikh, M. A., \& Del Valle, A. P. (2002). Duration of sexual arousal predicts semen parameters for masturbatory ejaculates. Physiology and Behavior, 76, 685-689.

Sankar, R., \& Archunan, G. (2004). Flehmen response in bull: role of vaginal mucus and other body fluids of bovine with special reference to estrus. Behavioural Processes, 67, 81-86.

Shackelford, T. K., \& Goetz, A. T. (Eds.). (2012). The Oxford handbook of sexual conflict in humans. New York: Oxford University Press.

Shackelford, T. K., LeBlanc, G. J., Weekes-Shackelford, V. A., BleskeRechek, A. L., Euler, H. A., \& Hoier, S. (2002). Psychological adaptation to human sperm competition. Evolution and Human Behavior, 23, 123-138.

Shackelford, T. K., Goetz, A. T., McKibbin, W. F., \& Starratt, V. G. (2007). Absence makes the adaptations grow fonder: proportion of time apart from partner, male sexual psychology, and sperm competition in humans (Homo sapiens). Journal of Comparative Psychology, 121, 214-220.

Simmons, L. W., \& Fitzpatrick, J. L. (2012). Sperm wars and the evolution of male fertility. Reproduction, 144, 519-534.

Soini, P. (1987). Sociosexual behavior of a free-ranging Cebuella pygmaea (Callitrichidae, platyrrhini) troop during postpartum estrus of its reproductive female. American Journal of Primatology, 13, 223-230. 
Tan, M., Jones, G., Zhu, G., Ye, J., Hong, T., Zhou, S., \& Zhang, L. (2009). Fellatio by fruit bats prolongs copulation time. PLOS ONE, 4, e7595.

van Rouen, J. H., Slob, A. K., Gianotten, W. L., Dohle, G. R., van Der Zon, A. T. M., Vreeburg, J. T. M., \& Weber, R. F. A. (1996). Sexual arousal and the quality of semen produced by masturbation. Human Reproduction, 11, 147-151.

World Health Organization. (2010). WHO laboratory manual for the examination and processing of human semen (5th ed.). Geneva: WHO Press.

Zavos, P. M. (1985). Seminal parameters of ejaculates collected from oligospermic and normospermic patients via masturbation and at intercourse with the use of a Silastic seminal fluid collection device. Fertility and Sterility, 44, 517-520.
Zavos, P. M., \& Goodpasture, J. C. (1989). Clinical improvements of specific seminal deficiencies via intercourse with a seminal collection device versus masturbation. Fertility and Sterility, 51, 190-193.

Zavos, P. M., Kofinas, G. D., Sofikitis, N. V., Zarmakoupis, P. N., \& Miyagawa, I. (1994). Differences in seminal parameters in specimens collected via intercourse and incomplete intercourse (coitus interruptus). Fertility and Sterility, 61, 1174-1176.

Ziegler, T. E., Epple, G., Snowdon, C. T., Porter, T. A., Belcher, A. M., \& Küderling, I. (1993). Detection of the chemical signals of ovulation in the cotton-top tamarin, Saguinus oedipus. Animal Behaviour, 45, 313-322. 